Recebido: 14/06/2019

Aprovado: 02/10/2019

DOI: $10.26512 /$ emtempos.v1i34.25124

\title{
Rupturas e continuidades no pensamento de Arthur Neiva acerca da imigração japonesa no Brasil entre 1920 e 1937
}

\author{
Ryo Kubohira (久保平 亮)
}

Resumo: O presente artigo tem como objetivo analisar as rupturas e continuidades no discurso ora favorável, ora desfavorável do médico sanitarista, intelectual e político Arthur Neiva acerca da imigração japonesa para o Brasil entre 1920 e 1937. Ao longo do texto, abordaremos as três fases do discurso de Neiva: um primeiro momento antijaponês entre 1910 e 1920; um segundo momento no qual ele mesmo se autoproclamou pró-japonês após retornar de uma viagem científica ao Japão em janeiro de 1921. E, devido às questões políticas que tangenciam o próprio espírito do Nacionalismo da década de 30, buscaremos apresentar uma terceira fase na qual ele assume um papel conservador juntamente com outros líderes de vertente antijaponês na Assembleia Nacional Constituinte de 1934. Assim, por meio do estudo de telegramas e jornais da época no Brasil e Japão, buscaremos compreender não apenas as "mudanças de lado" de Arthur Neiva, mas também, ao término, expor o próprio cerne do pensamento crítico sobre os imigrantes na Constituinte de 1934.

Palavras-chave: Arthur Neiva; movimento anti-japonês no Brasil; Nacionalismo.

\footnotetext{
* Bacharel em Letras pela Universidade de Estudos Estrangeiros de Quioto (KUFS). Mestre em Estudos de Língua e Cultura pela Universidade de Osaka (OU), ambas no Japão. Ex-intercambista de mobilidade acadêmica na Universidade de Brasília (UnB), na qual agradeço o constante apoio da professora dra. Tae Suzuki (LET-UnB). Contato: ryo14kubohir@gmail.com
} 
Abstract: The present article aims to study the ruptures and continuities in the sometimes favorable and sometimes hostile speech of the doctor, intellectual and politician Arthur Neiva about Japanese immigration to Brazil between 1920 and 1937. Throughout the text, we will approach the three phases of discourse of Neiva that starts from an anti-Japanese first moment between 1910 and 1920; a second moment in which he proclaimed as a himself pro-Japanese after returning from a scientific trip to Japan in January 1921. And, due to political issues that tangential the very spirit of Nationalism of the 1930s, as we seek to present a third to do in which he assumes a conservative role together with other leaders of anti-Japanese politicians in the National Constituent Assembly of 1934. Thus, through telegrams and newspapers of the time in Brazil and Japan, we will seek to understand not only "side" of Arthur Neiva, but also, at the end, to expose the very core of critical thinking about immigrants in the 1934 Constituent Assembly.

Keywords: Arthur Neiva; anti-Japanese movement in Brazil; Nationalism.

\section{Introdução}

Discípulo de Oswaldo Cruz, Arthur Neiva (1880-1943) ficou conhecido como um ilustre sanitarista e cientista na primeira metade do século XX, não só no Brasil, mas também no exterior, por conta de suas pesquisas sobre o barbeiro, insetos transmissores da doença de Chagas, profilaxia da malária e entomologia médica. Ao longo de sua vida, ele escreveu cerca de 180 textos acadêmicos que atualmente pertencem à Fundação Oswaldo Cruz (Fiocruz). Não obstante, o presente artigo buscará apresentar uma outra face de Neiva por meio de seu papel como político e articulador do pensamento contra a imigração japonesa para o Brasil entre as décadas de 1920 e 1930.

Nascido em Salvador, Neiva concluiu o curso de Medicina pela Faculdade de Medicina do Rio de Janeiro em 1903 e dirigiu diversas instituições científicas no Brasil, tais como Serviço Sanitário de São Paulo (1916-1918), Museu Nacional (1923-1927), Instituto Biológico do Estado de São Paulo (1927-1933) e Interventor Federal na Bahia (1931), dentre outras. Em 1933, assumiu a função de diretor do jornal carioca A Nação. Elegeu-se deputado federal para a Assembleia Nacional Constituinte e, no ano seguinte, foi reeleito deputado federal cujo mandato iniciado em 1935 foi interrompido pelo Estado Novo em $1937 .{ }^{1}$

Todavia, ainda que sua participação política tenha sido breve, este artigo analisará as causas que motivaram Arthur Neiva a transitar de um pró-japonismo depois de sua viagem ao Japão a convite do Instituto Kitasato em 1920 para alguém que chegou a acusar os imigrantes japoneses de ñindesejáveisò menos de uma década

\footnotetext{
${ }^{1}$ Verbete de Artur Neiva, na FGV CPDOC; KAIGAI Ká@GYá KABUSHIKI KAISHA, 1935, pp. 20-25. 
depois. Para atingir esse objetivo, faremos uma análise investigativa e comparativa em documentos históricos publicados tanto no Brasil como no Japão nas décadas de 1920 a 1930. Refletindo, assim, sobre uma suposta verdadeira face de Arthur Neiva que até agora não foi devidamente revelada.

Isto posto, começaremos por apresentar uma breve cronologia histórica do movimento anti-japonês no Brasil. Para, em seguida, estudarmos os relatos de Arthur Neiva sobre sua viagem científica ao Japão em 1920. Na terceira secção, buscaremos um estudo comparativo com a década anterior nos discursos anti-japoneses através dos Annaes da Assembléa Nacional Constituinte de 1934. E, por fim, concluir com um estudo sobre os fatores que contribuíram para a formação do seu pensamento contrário à imigração japonesa. Desta forma, a pesquisa buscará apresentar não apenas as transformações no pensamento de Arthur Neiva enquanto personagem histórico acerca do assunto, mas também demonstrar o que estava por detrás do movimento anti-japonês no Brasil e, por meio deste exemplo, como os imigrantes japoneses no Brasil foram vistos pelos intelectuais brasileiros da época.

\section{Uma breve cronologia da história do movimento anti-japonês: 1908-1934²}

Em dezembro de 1907, os Estados Unidos da América vetaram por meio do ñAcordo de Cavalheirosò a entrada de novos imigrantes japoneses, o que levou ao governo japonês a mudar sua estratégia de emigração dos Estados Unidos para o Brasil como um dos seus principais destinos. Assim, a chamada história da imigração japonesa no Brasil teve início no dia 28 de abril de 1908, quando o navio japonês ñKasato-maruò partiu de Kobe, trazendo os primeiros 781 imigrantes que aportaram em Santos no dia 18 de junho. Segundo KǾjama (1949: 428), deste momento histórico em 1908 até junho de 1941, aproximadamente 188.309 japoneses emigraram da terra do sol nascente para a terra onde canta o Sabiá.

Todavia, de modo geral, é largamente apresentado pela literatura internacional que muitas das vezes este grande influxo de imigrantes podem gerar questionamentos socioeconômicos e culturais dentro da comunidade local e também naquelas que se mudam, seja em busca de uma nova vida ou fugindo de uma realidade deixada para trás. Entretanto, o que é certo é que na primeira metade do século XX, a imigração japonesa não foi uma exceção e certamente não escaparia de ser alvo das críticas. Portanto, em oposição ao aumento súbito de imigrantes japoneses, vozes contra sua entrada passaram a aumentar no Brasil aos moldes da política adotada pelos Estados Unidos contra os ditos ñamarelosò.

\footnotetext{
${ }^{2}$ Para compreendermos os pontos essenciais, usamos como referência a seguinte fonte: JIHǽ, 29 de abril de 1934.
} 
Apesar de rumores terem começado logo quando os primeiros navios surgiram no horizonte do Atlântico, podemos dividir a questão anti-japonesa no Brasil em três etapas principais. A primeira onda anti-japonesa ocorreu em 1914, quando, após um período de experiência que visava verificar se os japoneses seriam adequados ou não ao trabalho nas lavouras, o então governador do Estado de São Paulo, Moraes Barros, julgou que os resultados foram insatisfatórios, suspendeu o recebimento de imigrantes japoneses em março do mesmo ano e cortou os subsídios para importação de nova mãode-obra com previsão até 1919. ${ }^{3}$ Proibição esta que se mostrou, na verdade, menos rígida do que no papel, e novos imigrantes continuaram a chegar.

A segunda etapa iniciou-se em 1923 e perpetuou até 1927. Na época em questão, os Estados Unidos demonstraram a intenção de enviar aproximadamente 200 mil negros domésticos à bacia do Amazonas para exploração e fundação de uma colônia. Para impedi-los, o deputado federal Fidélis Reis, eleito por Minas Gerais, apresentou à Câmara dos Deputados um projeto de lei que buscava proibir a entrada absoluta de imigrantes de cor negra e restringir a entrada de imigrantes de origem amarela por meio de uma cota anual correspondente a 3\% do total dos imigrantes já ingressos no Brasil.

Mesmo que o projeto de lei não tenha sido sancionado, ele conseguiu impedir o influxo de negros americanos para o Brasil, e, ao mesmo tempo, chamou a atenção para a questão da imigração japonesa, que veio por transferir o eixo da discussão de negros para japoneses. Vale dizer que, a partir da apresentação do projeto de Fidélis Reis no dia 22 de outubro, externaram-se na imprensa diversas opiniões favoráveis e contrárias aos imigrantes japoneses, e como a repercussão foi intensa, o projeto de lei passou pelo Comitê da Indústria e do Comércio e pelo Comitê Financeiro. Para, ao término, ser rejeitado em 1927, mas deixando junto à população, pelo menos a urbana, um latente sentimento anti-japonês (AOYAGI, 1941: 110-123).

A terceira etapa foi o debate sobre imigração dentro da própria Constituição de 1934, em reação direta à mudança da política externa japonesa que passou a tratar a emigração como uma política nacional a partir de 1925 e também uma reação ao crescimento no número de japoneses no Brasil de forma perceptível. Isso porque, entre 1925 e 1941, dois terços do total de pessoas que saíram do Japão vieram para o Brasil.

Todavia, como efeitos de problematizações internas e externas, o número de entradas da imigração japonesa começou a diminuir a partir de 1935 até resultar em apenas 1.350 pessoas em 1941 (UCHIYAMA\&TAJIRI, 1991: 85-86). Sendo que esta queda repentina foi causada tanto pelo corte das relações diplomáticas durante a Segunda Guerra Mundial como pela ideologia extensivamente disseminada naquele tempo: o Nacionalismo.

\footnotetext{
3 Além disso, também em 1917, brotou um discurso sobre a imigração japonesa na Câmara dos Deputados. O interpelante foi o deputado Maurício Paiva de Lacerda, e ele interrogou em torno do conteúdo do contrato da instalação de uma colônia japonesa em Iguape, São Paulo. (ANDá, 1949: 667; AOYAGI, 1941: 110)
}

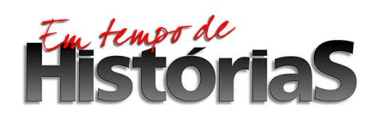


A década de 30 foi marcada pela Revolução de outubro de 1930, quando o então presidente Washington Luís foi afastado à força da presidência pelo golpe de Estado de Getúlio Vargas, que passou a chefiar o governo provisório entre 1930 e $1934 .{ }^{4} \mathrm{O}$ número de desempregados no Brasil elevava-se em virtude da Crise Mundial de 1929, de modo que crescia também as ideias nacionalistas. Nos anos 1930, o sentimento da antipatia pelos imigrantes estrangeiros infiltrava-se entre os brasileiros. Nesse contexto, em 15 de dezembro do mesmo ano, dois meses após a Revolução, Vargas sancionou a ordem de restrição à entrada de imigrantes estrangeiros por um ano para defender os desempregados nacionais. Mesmo assim, os imigrantes japoneses conseguiram escapar ao decreto, pois o alvo era a imigração urbana e não a agrária. Mantendo, assim, as altas taxas dos imigrantes japoneses e tornando-os mais eminentes do que outros imigrantes estrangeiros.

Depois da conquista do poder, Vargas começou a ressaltar uma ideologia de brasilidade nos aspectos sociais e culturais, e a exigir a assimilação e integração de todos os estrangeiros que residiam no Brasil sob a bandeira do nacionalismo baseado na centralização do poder. O Brasil era governado de modo ditatorial durante o governo provisório, mas, por outro lado, acumulavam-se vozes que defendiam o parlamentarismo pela promulgação imediata de uma nova constituição, dentre as quais provocaria a Revolução Constitucionalista de 1932 em São Paulo. Perante tal clima da época, o governo nomeou 26 membros de comissão encarregados de elaborar uma nova Constituição em 1933 e eles logo lançaram-se a formular as minutas da Constituição que iria substituir a de $1891 .^{5}$

A nova Constituição foi aprovada no dia 24 de maio de 1934 com a cláusula proposta por Miguel Couto em relação à restrição de novos imigrantes a $2 \%$ do total dos ingressantes já fixados no Brasil nos cinquenta anos anteriores à aprovação da lei (de 1884 a 1933). De tal forma que o número de imigrantes japoneses permitidos por lei se restringiria a 2.849 pessoas anualmente, uma vez que o número total de japoneses já residentes no Brasil era de 142.457 (JIHǽ, 3 de novembro de 1934). Embora essa restrição tivesse sido aplicada igualmente para todos os imigrantes estrangeiros, ela foi

\footnotetext{
${ }^{4}$ Até então, o Brasil era governado pelo regime oligárquico ñcafé com leite (1894-1930)ò e espalhava-se uma antipatia à oligarquia dominada por São Paulo e Minas Gerais. Os dois Estados conseguiram alternar o poder através de eleições fraudulentas. No início de 1929, surgiu uma cisão entre as duas grandes oligarquias devido à perfídia de Washington Luís, pois, nas eleições de 1930, embora fosse a vez de Minas Gerais designar o candidato para a presidência, ele decidiu arbitrariamente a candidatura de Júlio Prestes como sucessor. Descontentes, os políticos mineiros aliaram-se aos gaúchos e apoiaram Getúlio Vargas. Como consequência, depuseram à força Washington Luís da presidência e o poder se transferiu para Vargas. Com o sucesso de um golpe de Estado, acabou o domínio das oligarquias e iniciou o governo provisório por Getúlio Vargas entre 1930 e 1934. (FAUSTO, 2001: 178-183; MENDONÇA, 2000: 316-326; ANDǽ, 1983: 271-276)

${ }^{5}$ Após a publicação das minutas para a nova Constituição, realizou-se a eleição geral em 3 de maio de 1933 e elegeram-se 250 deputados. Deste modo, a inauguração da Assembleia Nacional Constituinte foi realizada em 15 de novembro, em que correspondia ao dia do início do Brasil República. (ASHIDA, 1934: 120)
} 
especialmente desfavorável para os japoneses, já que a imigração japonesa foi a mais tardia, iniciada em 1908, ou seja, apenas vinte e seis anos antes da lei.

Somente na década de 30, o governo japonês enviou para o Brasil mais de 20 mil japoneses, e como o número de entradas de imigrantes europeus diminuía, contrariando as expectativas de branqueamento da população como desejado por muitos, podemos dizer que a imigração japonesa foi a mais influente dentro da política de cotas. Não obstante, a aplicação da nova lei não foi imediata e também não incluía os menores de 14 anos entre os 2.849 imigrantes permitidos por lei. De tal forma que até 1937, efetivamente aproximadamente 5 mil japoneses conseguiram entrar no Brasil (AOYAGI, 1941: 139).

\section{Missão científica e suas impressões do Japão}

No dia 2 de julho de 1920, Arthur Neiva partiu do Rio de Janeiro a bordo do navio ñTosa-maruò para o Japão a convite do Instituto Kitasato, dirigido pelo bacteriologista Kitasato ShibasaburǾ(北里柴三郎, 1852-1931). Ele chegou em Kobe em 31 de agosto e permaneceu no Japão por quase dois meses. ${ }^{6}$ A viagem foi essencialmente científica, já que Neiva estava incumbido pelo governo paulista de estudar as organizações sanitárias no Japão e nos Estados Unidos e também a profilaxia da lepra na Noruega. Durante a missão científica, ele visitou várias cidades japonesas e fez uma série de conferências sobre os progressos da medicina e higiene no Brasil.

Pelo lado do governo nipônico, o motivo do convite era claro: propagar a situação real e estimular intercâmbio científico entre dois países. Por ocasião da realização do convite, o papel principal de intermediação foi desempenhado pelo parasitologista dr. Miyajima Mikinosuke (宮島幹之助) que visitara o Brasil em 1918, momento em que conheceu Arthur Neiva (Cf. LESSER, 1999: 94). No Japão, Neiva proferiu conferências e visitou hospitais, faculdades médicas e institutos, além de percorrer vinte e seis cidades dentre elas Hakone, Nikko, Nagoya, Yamada (Ise), Nara, Osaka, Quioto e Miyajima. ${ }^{7}$ Ao término, ele foi condecorado pelo governo japonês com $3 r d$ Class, Order of the Rising Sun, Gold Rays with Neck Ribbon (勲三等旭日中綬章) ${ }^{8}$, e partiu do porto de Kobe no dia 25 de outubro a bordo do navio ñKanada-maruò.

\footnotetext{
${ }^{6}$ Apesar do mesmo jornal, quanto ao roteiro de viagem não coincide. Em 12 de novembro, o JihǾnoticia que Neiva chegou em Kobe no dia 30 de agosto e foi para Tóquio no dia 5 de setembro. Contudo, o artigo de 10 de dezembro, escrito por Miyajima, informa de que Neiva chegou no dia 31 e foi para Tóquio no dia 6. Escolhemos aqui as datas a que Neiva e Miyajima se referiram na imprensa. (JIHá, 10 de dezembro de 1920; A NOITE, 7 de janeiro de 1921)

${ }^{7}$ JIHǽ, 10, 17 de dezembro de 1920; A NOITE, 7 de janeiro de 1921.

8 JIHá, 17 de dezembro de 1920. Sobre a imagem, Vide: Gabinete do primeiro-ministro japonês. Disponível em <https://www8.cao.go.jp/shokun/shurui-juyotaisho-kunsho/kyokujitsusho.html>
}

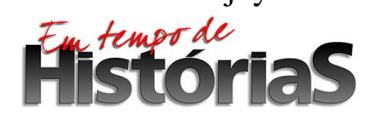


Após passar seis meses em viagem científica, aportou no Rio de Janeiro em 7 de janeiro de 1921. Já nesse momento, começou a propagar sua nova vertente favorável aos japoneses, conforme o fragmento a seguir demonstra:

\begin{abstract}
Para ser franco, talvez já saibam muito bem que eu fui um dos que não sentiam muita simpatia pela etnia japonesa até visitar o Japão. Falando com franqueza, eu não simpatizava com a etnia japonesa e até tinha ideias anti-nipônicas.(...) Uma boa impressão sobre a etnia japonesa me levou a me transformar em pró-japonês no sentido verdadeiro, e teve efeito para me tornar atualmente pró-japonês, mudando por completo meus sentimentos anti-japoneses do ano passado. ${ }^{9}$
\end{abstract}

De acordo com o que ele próprio disse, Neiva viajou para o Japão como um antijaponês e regressou ao Brasil como pró-japonês. Aqui, podemos perceber a primeira mudança de ideias de Neiva por ocasião dessa viagem ao Japão. Sobre as razões pelas quais ele foi anti-japonês, ressaltamos que ele mesmo confessou ser por causa da noção preconceituosa e falta de conhecimento sobre os japoneses que havia no Brasil. A isto, ele adicionou que não era o único e que os outros brasileiros também estariam na mesma situação.

Depois de voltar ao Brasil, suas atividades ficaram cada vez mais intensas. Neiva disse que já tinha pensado, enquanto estava em Tóquio, como deveria mostrar ao Brasil o seu agradecimento ao Japão. E, em um desabafo, disse que ño meu agradecimento deverá ser expresso por fazer todo o possível para defender e auxiliar a etnia japonesa que vive no Brasil e apresentar ao Brasil uma grande etnia que é a japonesa, fazendo propaganda da sua verdadeira importânciaò ${ }^{10}$

Do mesmo modo, Neiva se esforçou em defender o Japão e sua cultura por meio de discursos e publicações na imprensa. Ele até pretendia publicar um livro, mas este projeto não se realizou (JIHá, 4 de fevereiro de 1921). Um outro exemplo, embora fracassado, foi sua intenção de convidar um químico japonês para estudar no Brasil enquanto era responsável pelo Instituto Butantan (1919-1921) (JIHá, 15 de julho de 1921). Foi assim que Arthur Neiva quis expressar o seu agradecimento pelo país do sol nascente, porém este período de lua-de-mel não durou muito, pois logo na década seguinte ele veio a se mostrar novamente crítico à imigração japonesa ao ponto de aliar-

9「已に御熟知でもあらむが、最近余が渡日する迄は、眞實の事を言はば、余は日本民族に對し て餘り好意を持つて居なかつた一人である。忌憚なく言ふと、寧ろ余は日本民族に就而好くな い印象を抱き、排日的思想を持つて居た者である。（é ）此間日本民族より受けた余の好印象 は余を驅つて眞の意味に於ける親日者たらしめ昨年の排日は掌を㼑すが如く今の親日者と化さ しむる効果があつたのである。」[tradução nossa] (JIHáe 28 de janeiro de 1921: ñ排日から親日に變つた子一バ氏の日本視察感想談ò)

10 「余の感謝の念は、伯國内に居住する日本民族を余の能ふ限ぎりに於て擁護援助し亦た日本 民族と云ふ偉大なる民族を伯國に紹介し其眞價を宣傳する事に依りて表現せられねばならぬ。 $」$ [tradução nossa] (JIHǽ, 28 de janeiro de 1921) 
se a Xavier de Oliveira, Monteiro de Barros e Miguel Couto na outrora mencionada taxa de $2 \%$ para imigrantes, cuja sanção no dia 24 de maio de 1934 contou com 146 votos a favor e 41 contra (JIHǽ, 26 de maio de 1934).

\section{De grande sanitarista a político ñanti-japonêsò}

A esta secção, cabe buscar compreender quais os elementos levaram Arthur Neiva a mudar de ideia novamente, ou melhor, retornar à sua posição anti-nipônica. Vejamos primeiramente quais os argumentos foram proferidos por Neiva na ocasião da Assembleia Nacional Constituinte, em especial, por meio de sua própria emenda de $n$. 1.053 que estipulava que ñsó será permitida a imigração de elementos da raça branca, ficando proibida a concentração em massa, em qualquer ponto do paísò (ANNAES, 1935: 211).

Em sua exposição no dia 3 de fevereiro de 1934, Neiva justificou que advogava a restrição da entrada da imigração japonesa não só por questões raciais, mas por questões políticas e de salvaguarda nacional. E continuou dizendo que a entrada de japoneses em massa representaria uma ameaça à soberania nacional e alertou aos deputados que se deixassem a oportunidade de limitá-los fugir, o Brasil transformar-seia numa nova Manchúria. Em outras palavras, sua maior preocupação consistia no latente militarismo japonês no leste asiático (GAIMU SHǽ, 1933: 960; JIHá, 29 de abril de 1934; UEHARA, 1934: 10).

Conforme foi referido, a década de 1930 foi palco do nacionalismo em diversas partes do mundo, e tais ideias disseminavam-se e penetravam tanto no Brasil como no Japão. Entretanto, o nacionalismo do Japão era muito mais visível e latente por duas razões: o Incidente da Manchúria (de 1931 a 1933) e a Saída da Liga das Nações (1933). Sobre isso, Neiva afirmou:

O Japão, desligando-se da Liga das Nações, que em peso se levantou contra ele, e desafiando os Estados Unidos, se apoderou, a mão armada, de toda a Manchúria, com mais de dois milhões de quilômetros quadrados, maior ainda que a Amazônia, e com quarenta milhões de habitantes (ANNAES, 1935: 215).

Em particular, o Incidente de Mukden, também chamado de Incidente da Manchúria, produziu forte impacto na comunidade internacional incluindo os brasileiros anti-japoneses que identificaram a Manchúria como o seu próprio território no futuro. Segundo Geraldo (2009a: 186), ñNeiva defendia a preferência por trabalhadores nacionais especialmente para a exploração econômica na região da Amazônia. A Amazônia foi repetidamente comparada com a Manchúria, a qual havia sido invadida pelos japonesesò. Deste modo, é possível perceber como Neiva via a Manchúria

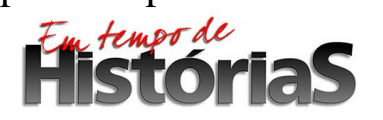

(PPGHIS/UnB) No. 34, Brasília, Jan - Jul 2019 ISSN 2316-1191 
ocupada na época pelo Japão como a Amazônia no futuro próximo se as imigrações continuassem.

Através desses fatos, entre 1931 e 1933, Neiva começou a cogitar como o Japão poderia invadir a Amazônia e conquistá-la assim como aconteceu na Ásia, e passou a problematizar o assunto como uma ameaça à segurança nacional. A sua preocupação não era a mera teoria. Por volta de 1930, o Japão sofria repetidas crises devido a diversos fatores internos e externos. De forma que, em 1932, o governo japonês começou a subsidiar os imigrantes japoneses com 50 ienes por pessoa para preparativos, além do custo de passagem para enviá-los ao Brasil. Por conseguinte, o número de imigrantes japoneses ultrapassou mais de 20 mil pessoas só em 1933 e 1934 (UCHIYAMA\&TAJIRI, 1991: 100). Perante tal crescimento vertiginoso da imigração japonesa, Neiva andava apreensivo e escreveu assim:

Se continuarem no entanto, a entrar na proporção que vai se aproximando de 30 mil japoneses por ano, teremos ao cabo de um decênio, cerca de 300 mil japoneses, que adicionados aos já existentes e seus descendentes, formarão um núcleo superior a meio, milhão de japoneses, que aos poucos deslocarão o trabalhador nacional, o que será fácil, e mais tarde o próprio italiano e sírio, como aliás já vai ocorrendo (ANNAES, 1935: 214-215).

Como Arthur Neiva preferia trabalhadores nacionais para a exploração econômica da Amazônia, a chegada dos japoneses em massa foi significativamente inconveniente ao ponto de ele mesmo dizer que eles, os japoneses, deviam ser recusados intensamente. ${ }^{11}$ Assim, de forma sucinta, notamos nos argumentos de Arthur Neiva na sessão do dia 2 de fevereiro de 1934 os seguintes pontos:

1. Revelando a sua própria preferência pela raça branca;

2. Mesmo que os japoneses fossem uma etnia com ñaltas qualidades de cultura, disciplina, organização e capacidade de trabalhoò (ANNAES, 1935: 214), não era possível permitir a sua entrada massiva, pois eles prejudicariam os trabalhadores nacionais;

\footnotetext{
${ }^{11}$ Embora não possamos tratar neste artigo dos aspectos raciais dos discursos anti-japoneses de Arthur Neiva, é inegável que ele os usava como um dos argumentos principais contrários à imigração japonesa. Já que a estipulação como ñgarantia da integração étnica e capacidade física e civil do imigranteò, que foi inserida no parágrafo 6 do artigo 121, era indispensável do ponto de vista do nacionalismo (texto de Constituição de 1934. Vide: Referências Bibliográficas, secção Documentos oficiais, jornais e revistas). Portanto, é possível indicar esse tipo de perspectiva tanto na emenda (n.1.053) como na justificação de Arthur Neiva: గ̃Porém, por mais que admire os nipões, muito mais amor consagra à Pátria que se deve precaver contra uma colonização de povo de mentalidade estranha, de língua diversa, religião diferente e positivamente inassimilável, até nas regiões asiáticas, onde vivem encerrados em concentração [...]ò. (ANNAES, 1935: 214)
}

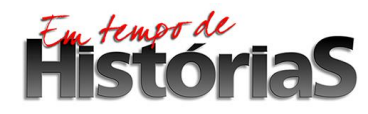


3. Sentimento de extrema ameaça contra a expansão geográfica e a verossímil invasão da Amazônia pelo Japão. ${ }^{12}$

Desta maneira, Arthur Neiva enumerava várias razões para criticar os japoneses, até mesmo trazendo à tona alguns assuntos sem fundamentos, por exemplo, ao dizer que os imigrantes já estabelecidos no Brasil nada contribuíam para a economia local e exportavam tudo de volta para o Japão. ${ }^{13}$ De tal modo que diferentemente da década de 1920, ele passou a ser considerado pelos meios de comunicação japonesa como uma ñpessoa impulsivaò ao longo dos anos de 1930 (JIHǽ, 24 de fevereiro de 1934; NIPPON SHIMBUN, 7 de março de 1934).

\section{Reflexões sobre as causas do sentimento ñanti-japonêsò}

Enfim, quais foram as motivações que nortearam uma mudança de ideias acerca dos imigrantes japoneses em Neiva? Como ele mesmo disse orgulhosamente que ñninguém tem maior admiração pelo Japão do que o signatário, pois bem os conhecia e também sua maravilhosa históriaò (ANNAES, 1935: 215). Neiva observou o Japão com os seus próprios olhos e até recebeu o grau da condecoração do governo japonês. Não obstante, acabou sendo um dos deputados mais veementes e anti-japoneses por ocasião da lei de cotas de 1934. Eis aí a dúvida deste artigo. Isto é, não teriam outras causas mais palpáveis para essa mudança de atitudes? Sob esse ponto de vista, nesta última secção examinaremos as possíveis causas para esta mudança de mentalidade.

Antes de mais nada, convém relembrar o processo de formação do sentimento anti-japonês de Arthur Neiva, já que originalmente ele era anti-japonês. Em outras palavras, poderíamos dizer que os seus sentimentos para com o Japão realmente se transformaram por meio da viagem? Ou, como se escreveu em telegramas diplomáticos japoneses da época, de que Neiva fingia ser um pró-japonês (GAIMU SHá, 1933: 960). No que tange a isso, me parece que Neiva não se fingia ser pró-japonês nos idos de 1920, porque certamente ele demonstrava, ainda que momentaneamente, um certo tipo de simpatia pelo Japão.

Assim, com base em documentos da época, advogo que Neiva era de fato um admirador do Japão, ainda que somente por um curto período de tempo após sua volta. Nos dias de hoje, dado nosso deslocamento temporal, podemos observar como ele agia por meio dos artigos registrados no acervo digital. E, conforme prometido por ele mesmo, é certo que ao chegar no Brasil ele se engajou em colaborar com os jornais

\footnotetext{
${ }^{12}$ Sobre os artigos em japonês, Vide: JIHǽ, 24 de janeiro de 1934; 17, 21, 23 de fevereiro de 1934.

${ }^{13}$ ñOs japoneses constituíram grandes núcleos de colonização em São Paulo, [...] tudo trabalhado por filhos daquele país e o produto por eles plantado e colhido é transportado em vapores também japoneses para a mãe pátria. Jamais aqui suscitaram nenhuma plantação de chá ou criação de bicho de seda, porque, se tal fizessem, iriam ferir os interesses do Japão, [...]ò. (ANNAES, 1935: 215)
} 
cariocas sobre suas impressões da viagem ao Japão. Na verdade, exatamente no dia em que ele regressou ao Rio de Janeiro em 7 de janeiro pela manhã, ele já relatou as suas admirações pelo Japão no jornal $A$ Noite ${ }^{14}$, dizendo assim: ñTrago do Japão as recordações mais gratas, pois fui cumulado das maiores gentilezas por parte do governo, dos médicos e dos cientistasò (A NOITE, 7 de janeiro de 1921). Todavia, muitos jornais cariocas não publicavam sequer um terço do que Neiva escrevia e alguns outros jornais nada publicavam.

Perante tal resistência dos jornais, Neiva cogitou que isso era parte do alinhamento das editoras à propaganda dos Estados Unidos contra os ditos ñamarelosò, e que os mais diversos artigos publicados cotidianamente nos jornais brasileiros com um espírito anti-japonês não passavam de publicidade direta Norte-americana. Isso porque, naquela época, os Estados Unidos pretendiam implantar seu capitalismo imperialista na América Latina. Portanto, a existência dos japoneses que foram se enraizando no raio de suas atividades era deveras inconveniente. Consciente da infiltração da propaganda anti-japonesa dos Estados Unidos no Brasil, Arthur Neiva fez a seguinte declaração:

Mas farei o meu melhor! Não gosto do capitalismo norte-americano por natureza. Sou contra os Estados Unidos desde a infância, e as suas tendências exageradas não me agradam. Os Estados Unidos são ideologicamente meu adversário pessoal e, ao mesmo tempo, o inimigo público da etnia japonesa. Por esse objetivo comum estou decidido a lutar mesmo que sozinho. ${ }^{15}$

Como prova disso, Neiva conseguiu chegar a um acordo para publicar regularmente artigos pró-nipônicos em periódicos do O Estado de São Paulo e na Revista do Brasil ${ }^{16}$ (JIHá, 4 de fevereiro de 1921). A despeito disso, e contraditoriamente, dez anos depois ele viria a se tornar o diretor do jornal A Nação, pelo qual circulava cada vez mais ativamente as teses anti-japonesas. ${ }^{17}$ Isso porque Arthur Neiva não se fingia de pró-japonês tampouco veio a fingir ser anti-japonês, independente de que lado estivesse, ele trabalhou arduamente para ser ouvido. Assim,

\footnotetext{
${ }^{14}$ ñComo o Japão ficou conhecendo os progressos da hygiene entre nósò em A NOITE, 7 de janeiro de 1921.

15「然し余はやる! 北米の資本主義は元来から余の腹の虫が好かぬ。幼時より余は反米思想を 抱いて居る者で、何彼と渠等の誇大傾向を好まめ。余の思想上個人的敵である北米は亦た同時 に日本民族の公敵である。余は此の共同の目的の爲めに単身闘はふと決心して居る。」[traduçã o nossa] (JIHǽ, 4 de fevereiro de 1921)

${ }^{16}$ Já em fevereiro de 1921, Neiva publicou suas impressões do Japão na Revista do Brasil, dirigido por Monteiro Lobato. Vide: REVISTA DO BRASIL, n. 62, 1921, pp. 94-95: ñViagens O Japão visto pelo dr. Arthur Neivaò.

17 Sobre A Nação, Vide: BNDigital. Disponível em <http://bndigital.bn.gov.br//acervo-digital/ANacao/120200>. No telegrama diplomático de 28 de dezembro de 1933, o embaixador Hayashi criticou severamente o caráter e a duplicidade de ações habituais de Arthur Neiva, que fez jornalistas do A Nação escreverem artigos anti-japoneses. (Cf. JIHǽ, 29 de abril de 1933)
}

\section{Filstorias}


conforme mencionado acima, Arthur Neiva passou de uma pessoa que advertia que a propaganda anti-japonesa dos Estados Unidos se infiltrava em grande escala no campo de jornal brasileiro como uma erva daninha na década de 20, para ser ele mesmo um escritor e o diretor de uma empresa jornalística enraizada nas ideias contrárias aos imigrantes japoneses na década de 30 .

Então, desde quando Arthur Neiva mudou de ideias? A esse respeito, não há provas conclusivas, mas existem exposições convincentes. Através dos Annaes da Assembléa Nacional Constituinte, verificamos como ele estava receoso com o militarismo e expansionismo do Japão e que isso pudesse chegar até o Brasil. Contudo, em um texto publicado mais de dez anos antes da Assembleia de 1934, Neiva dizia o contrário. Para ele, ñObservando pormenorizadamente a situação real da vida dos japoneses durante minha permanência lá, encontrei os verdadeiros motivos pelos quais eles teriam que se expandir para o exterior. Isto porque foi proveniente das vozes verdadeiramente iminentes de suas vidas, e fiquei sabendo então que eles não vinham com as mesmas intenções territoriais que os norte-americanos [...] o. $^{18}$

Ou seja, é certo que alguma coisa aconteceu com ele entre 1921 e 1933 que fez uma mudança dramática em seu pensamento. Para responder a esta pergunta, farei jus a três motivos, que não são necessariamente excludentes, mas, em última instância, complementares e dialogam com a complexa e cíclica vida de Arthur Neiva.

O primeiro indício foi um telegrama da United Press (UP) enviado de Tóquio em 8 de abril de 1933, no qual estava escrito que os imigrantes japoneses enviados ao Brasil seriam redistribuídos para a Manchúria. No telegrama enviado para o Ministro Uchida KǾai (内田康哉) de 10 de maio de 1933, o então embaixador do Japão no Brasil Hayashi Kyا̃ jirǾ(林久治郎) manifestou uma preocupação com o agravamento da situação que o telegrama sem fundamentos da United Press poderia causar nas relações Nippo-Brasileiras (GAIMU SHǽ, 1933: 949).

Hayashi acreditava que os brasileiros que eram simpatizantes ao Japão poderiam ficar contrariados por julgar que o Brasil estivesse sendo menosprezado. Ao mesmo tempo em que os contrários ao Japão veriam isso como plano de possível investida sobre o Brasil no futuro. ${ }^{19}$ Além disso, ele estava apreensivo com os rumores de que houvesse o apoio do exército por detrás dos imigrantes japoneses (GAIMU SHǽ, 1933: 947, 953-954). Assim, Hayashi previa a perda do apoio dos pró-japoneses e o fortalecimento dos anti-japoneses que já estavam desconfiados com os imigrantes japoneses. É provável que o telegrama da United Press também tenha instigado Arthur

18 「滞日中詳らかに日本民族の生活實相を視て、日本民族が海外發展をしなければならぬ理由 に逢着した。之れは日本民族の生活の眞の要求から来たもので、北米人等中傷の如き領土侵略 的でないことを徹底的に知つた、（é ）」[tradução nossa] (JIHáe 28 de janeiro de 1921)

${ }^{19} \mathrm{O}$ governo japonês negou-se, mas o exército insistiu em interromper o envio de imigrantes para o Brasil e centralizar nova política colonial em Manchúria, destinando todo o custo de incentivo da imigração ao Brasil. (KOKUSEI SHIRYá, 1934: 2) 
Neiva, já que tinha uma clara antipatia à colonização da Amazônia tal como a Manchúria, e uma desconfiança ao militarismo japonês.

O segundo indício que abordaremos foi apresentado pelos jornalistas japoneses da época sobre a atitude indiferente das autoridades japonesas no Brasil. Conforme Onaga Josei (翁長助成), fundador do jornal Nippon Shimbun, um dos principais locutores deste momento, pode-se dizer que as autoridades oficiais e pessoas envolvidas no empreendimento imigratório tratavam Arthur Neiva com antipatia, e dizem que até os funcionários de embaixada do Japão no Rio de Janeiro não visitaram a sua casa nem o cumprimentaram mesmo quando se encontravam na rua. No dizer de Onaga, se as autoridades nipônicas no Brasil tivessem se comunicado amigavelmente com Neiva, talvez ele não tivesse se tornado um dos principais idealizadores do projeto de lei antijaponês. Pois, que frente a falta de empatia daqueles que ele buscou defender, e após ser recebido com frieza, seria natural voltar ao seu estado anti-japonês antes da viagem para o Japão, visto que, segundo Onaga, ele era uma ñpessoa impulsivaò(NIPPON SHIMBUN, 7 de março de 1934).

O terceiro indício foi, por fim, um encontro informal com Cordell Hull, então Secretário de Estado dos Estados Unidos. De acordo com as notícias da época, depois de participar de Conferências Pan-Americanas realizadas em Montevidéu em outubro de 1933, Hull passou pelo Rio de Janeiro e convidou Arthur Neiva para uma pescaria de um dia inteiro (JIHǽ, 20 de junho de 1934). ${ }^{20}$ Infelizmente, pouco sabemos sobre o que eles conversaram dado o carácter informal, ou melhor, sigiloso do encontro, porém é muito provável que também tocaram em assuntos políticos, pois não podemos deixar de notar que as atividades contrárias à imigração japonesa de Arthur Neiva se intensificaram muito logo após esse encontro.

Estudando textos publicados em português e japonês, notamos como os autores apresentaram a existência de certas ñmanobras políticasò dos Estados Unidos. ${ }^{21}$

Exemplos deste estratagema são os seguintes: uma conduta suspeita da Fundação Rockefeller que ofertava um grande fundo à medicina brasileira; a tomada de posse de Hugh Simons Gibson como embaixador extraordinário e plenipotenciário; e rumores de que Edwin Vernon Morgan, era ex-embaixador dos Estados Unidos no Brasil (19121933), iria investir uma grande quantia de dinheiro no Brasil, dentre outros (GAIMU SHá, 1934: 885).

\footnotetext{
${ }^{20}$ Em artigos publicados no Japão, a figura mencionada é diferente. Nos jornais Tokyo Nichi Nichi Shimbun e Osaka Mainichi Simbun, ambos publicados no mesmo dia, o personagem é noticiado como o então ministro britânico das Relações Exteriores John Allsebrook Simon, $1 .^{\circ}$ Visconde Simon. Conforme esses jornais, Simon teve encontro com pessoas influentes brasileiras quando visitou o Brasil em 1934. Nessa ocasião, ele foi pescar todo o dia com Miguel Couto e Arthur Neiva e realizou um encontro informal (TOKYO NICHI NICHI SHIMBUN, 26 de maio de 1934; OSAKA MAINICHI SHIMBUN, 26 de maio de 1934). Neste artigo, usamos o artigo de JihǾno dia 20 de junho de 1934 porque este é mais detalhado que aqueles publicados no Japão.

${ }^{21}$ GAIMU SHǽ, 1934: 884-885, 918-919; JIHǽ, 29 de abril de 1934; 13, 16, 20, 23 , 27 de junho de 1934.
} 
As principais razões pelas quais os Estados Unidos agiam por trás do Brasil podem ser consideradas de ordem econômica. Isso porque, na época em questão, os ñartigos amarelosò expandiam-se no mercado mundial e ameaçavam o monopólio dos Estados Unidos e da Grã-Bretanha, que ficavam apreensivos com as condutas a seu belprazer e sentiam-se desagradáveis à introdução e aumento de produtos japoneses no Brasil (JIHá, 29 de abril de 1934; 13 de junho de 1934).

Ainda sobre Hugh Simons Gibson, antes de tomar posse em 1933, ele já havia participado da Conferência Naval de Londres em 1930 como delegado e da Conferência para o Desarmamento em Genebra de 1932 a 1933 como delegado interino da delegação americana. Era um homem internacionalmente conhecido e considerado proeminente diplomata, por isso mesmo que Gibson foi encarregado de lidar com os assuntos econômicos. Nos anos de 1930, paralelamente à expansão de produtos japoneses, o Japão pretendia comprar do Brasil a produção de algodão bruto e firmar um acordo de comércio bilateral. Os Estados Unidos opuseram-se ao plano do Japão, pois havia receio de que o Japão entraria no mercado brasileiro e roubaria um dos seus melhores clientes: o Brasil (NIPPON SHIMBUN, 11 de abril de 1934. Cf. JIHǽ, 13 de junho de 1934). Assim, enfrentando grande perigo em relações comerciais, os Norte-americanos foram obrigados a tomar atitudes contra o Japão no sentido de salvaguardar os seus interesses e estreitar seus laços com o Brasil.

\section{Considerações finais}

O sentimento anti-japonês apareceu no Brasil já na primeira metade da década de 1910 e durou pelo menos até a Segunda Guerra Mundial, exacerbando-se à medida que ia se reforçando a centralização do poder. Nesse sentido, pode-se dizer que o movimento anti-japonês foi um dos efeitos do Nacionalismo da época. Influenciando, inclusive, Arthur Neiva, pois é certo de que suas contundentes críticas ao militarismo japonês na Assembleia Nacional Constituinte de 1934 seriam emitidas do seu ponto de vista da defesa dos interesses nacionais.

Vale ressaltar que em 1921, ainda na fase pró-Japão, Neiva já havia percebido e questionado o governo japonês sobre a ausência de política bilateral clara e definida para com o Brasil, não apenas pela imigração (JIHá, 28 de janeiro de 1921). E apesar das constantes indicações dele, o Japão não tomava nenhuma atitude concreta e a situação mantinha-se instável. Em contraponto, sobretudo após o Japão ter adotado a imigração como parte da política nacional em 1925, o número da entrada de imigrantes japoneses aumentava cada vez mais. A isto, acresce que o Japão começou a mostrar tendências não só de nacionalismo, mas também de militarismo e até expansionismo por volta da década de 1930 sobre a mencionada Manchúria. Assim, não é de surpreender que Arthur Neiva tenha passado a sentir-se ameaçado pelos interesses japoneses.

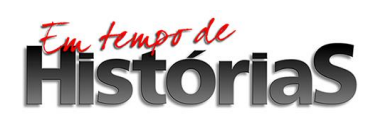


Neste artigo, também buscamos apresentar por meio de fontes históricas como jornais e telegramas da época, o backstage do movimento anti-japonês no Brasil e como esteve intrinsecamente envolvido com os interesses dos Estados Unidos da América, mais precisamente, por meio das ñmanobras políticasò desde os anos de 1920. Sobre este assunto, segundo o telegrama de 15 de março de 1934, o movimento anti-japonês no Brasil ñpode ser entendido, por um lado, como parte da campanha propagandista dos Estados Unidosò. ${ }^{22}$ E em outro telegrama datado de 10 de maio de 1934 no qual se escrevia assim: ñendo em vista o fato de que jornais e telegramas que poderiam dar origem a causas de controvérsia com o Japão até agora no Brasil têm sido abastecido com toda a probabilidade da United Press (...) Q $^{23}$ Portanto, podemos pensar que os motivos pelos quais Neiva se posicionou contra a imigração japonesa passam pelo seu medo de uma colonização da Amazônia como uma nova Manchúria e a ameaça do militarismo japonês que possivelmente foi influenciado pela United Press, ou melhor, pelos Estados Unidos.

Além do mais, este artigo também buscou ressaltar razões de cunho pessoal sobre suas atitudes anti-japonesas: a indiferença das autoridades oficiais japonesas no Brasil. Pois, como dizem, nada pode vir do nada. Está relatado inclusive que o então embaixador Hayashi viajou para a Amazônia pouco antes da aprovação da lei de cotas de 1934 e desagradou muito aos moradores japoneses no Brasil, isso porque, segundo o jornal japonês Tokyo Nichi Nichi Shimbun, Hayashi afirmou que ños japoneses que vivem no Brasil por vinte e cinco anos teriam semeado o próprio movimento antijaponês vindouroò ${ }^{24}$ De fato, diversos disparates cometidos pelos imigrantes japoneses no Brasil eram conhecidos pelas autoridades locais, porém, ao que tudo indica, este é um campo ainda para ser melhor explorado pela historiografia brasileira em prol de definir até que ponto o movimento anti-japonês foi realmente influenciado por possíveis ñmaus exemplosò ou mesmo ñmovimentos anti-japonesesò entre os próprios imigrantes e descendentes de japoneses no Brasil.

Concluindo, considerando a vida e os argumentos favoráveis e desfavoráveis de Arthur Neiva, chegamos à conclusão de que, mesmo que retratado como uma ñpessoa impulsivaò, ele não se fingiu ser pró-japonês em 1920 tampouco se fingia ser antijaponês depois isso. Isso porque, conforme já foi referido, após sua viagem ao Japão, Arthur Neiva se mostrou efetivamente interessado em compreender a realidade do Japão. Em sua entrevista para o jornalista japonês Wada DengorǾ(和田傳五郎 $)^{25} \mathrm{em}$ 1935, Neiva afirmou que ñão era possível desdizer esta convicção, porque não fazia (as

22 「一面二於テ北米ノ外交戦トモ見得へク（é ）」[tradução nossa] (GAIMU SHǽe 1934: 885)

23 「従来伯國二於テ對日物議ノ種子トナリタル新聞電報カ十中八九ユーナイテッド・プレスニ ヨリ供給セラレ居ル事實二鑑ミ（é ）」[tradução nossa] (GAIMU SHǽ, 1933: 954)

24 ○十五年間在留の日本人が寄ってたかって排日の種を蒔いていたのだ（é ）」[tradução nossa] (TOKYO NICHI NICHI SHIMBUN, 26 de maio de 1934)

${ }^{25}$ Wada Dengorǿ correspondente especial do jornal Tokyo Nichi Nichi Shimbun.

\section{Fististorias}


ações para a aprovação da lei de cotas) por impulso momentâneoò. ${ }^{26}$ Portanto, não seria pertinente considerá-lo como um anti-japonês xenofóbico que recusa tudo o que é diferente, mas sim como um intelectual que frente a certas informações, algumas delas incoerentes como sabemos hoje, foi levado ao conservadorismo e nacionalismo típico de sua época, e para isso adotou uma linha mais dura quanto à imigração japonesa para o Brasil.

\section{Referências Bibliográficas}

ANDǽZZenpati. ñ̃urajiru no Kokka Syugi to Nihon Imin Seigenò. In: Imin Yonjî Nen shi. São Paulo: KǾjama RokurØ 1949, pp. 664-678. Disponível em <http://www.brasiliminbunko.com.br/iminbun co_capa1.htm> Acesso em: 1 de abril de 2019.

Burajiru Shi. Tóquio: Iwanami Shoten, 1983.

AOYAGI IkutarǾ Burajiru ni okeru Nihonjin Hatten shi (JǾ. Tóquio: Burajiru ni okeru Nihonjin Hatten Shi KankǾIinkai, 1941. Disponível em 〈http://www.brasiliminbunko.com.br/iminbunco _capa1.htm〉 Acesso em: 1 de junho de 2019.

ASHIDA Hitoshi. Burajiru no Imin Seigen. In: Keizai æærai. Tóquio: Nippon Hyǿon Sha, vol. 9, n.7, pp. 117-124, 1934.

COUTINHO, Amélia. Verbete de Artur Neiva, na FGV CPDOC (Fundação Getúlio Vargas Centro de Pesquisa e Documentação de História). Disponível em <http://www.fgv.br/ cpdoc/acervo/dicionarios/verbete-biografico/neiva-artur> Acesso em: 15 de maio de 2019.

FAUSTO, Boris. História concisa do Brasil, São Paulo: Edusp, 2001.

GERALDO, Endrica. ñA đ́ei de cotasôde 1934: controle de estrangeiros no Brasilò. Cadernos AEL 15 (27), 2009. Disponível em <https://www.ifch.unicamp.br/ojs/index.php/ael/article/view/2575> Acesso em: 12 de maio de 2019.

ñO combate contra os áquistos étnicosô identidade, assimilação e política imigratória no Estado Novoò. Locus: Revista de História. Juiz de Fora, v. 15, n. 1, p. 171-187, 2009b. Disponível em <http://www. ufjf .br/locus/files/2010/02/337.pdf> Acesso em: 27 de maio de 2019.

Kaigai KØ̆gýKabushiki Kaisha [KKKK] (org.). Hakukoku Tyomei Seiji ka Ryakuden. Tóquio: Kaigai KǾgyØ 1935.

KOKUSEI SHIRYá ñ Burajiru no Imin Seigen hǾSeitei Jijǿni tsuiteò, autor desconhecido, Nishino Seimu Ch@́a Kyoku, pp. 1-29, vol. 4, n. 7, 1934.

KáY AMA RokurǾ Imin Yonjī Nen shi, São Paulo: KǾyama RokurǾ 1949.

LESSER, Jeffrey. Negotiating national identity: immigrants, minorities and the struggle for ethnicity in Brazil. Durham, N.C: Duke University Press, 1999.

MENDONÇA, Sônia Regina de. ñEstado e sociedade: a consolidação da república oligárquicaò. In: História geral do Brasil. Linhares, Maria Yedda (org.), pp. 316-326. Rio de Janeiro: Elsevier Editora, 2000.

RAMOS, Jair de Souza. ñDos males que vêm com o sangue: as representações raciais e a categoria do imigrante indesejável nas concepções sobre imigração da década de 20ò. In: Raça, ciência e sociedade. MAIO, Marcos Chor \& SANTOS, Ricardo Ventura (orgs.), pp. 57-80. Rio de Janeiro: Editora FIOCRUZ, 1996.

26 「余は一時的の氣持でやつたのでないからこの信念を翻すことは出来ない。」[tradução nossa] 
REZENDE, Joffre Marcondes de. À sombra do plátano: crônicas de história da medicina [online]. São Paulo: Editora Unifesp, 2009. Arthur Neiva, inteligência e cultura a serviço da nação. pp. 355-358.

<http://books.scielo.org/id/8kf92/pdf/rezende-9788561673635-42.pdf> Acesso em: 11 de junho de 2019.

SKIDMORE, Thomas. Preto no branco: raça e nacionalidade no pensamento brasileiro. Rio de Janeiro: Paz e Terra, 1976.

STEPAN, Nancy. ñEugenics in Brazil, 1917-1940ò. In: The Wellborn Science, M. Adams (org), pp. 110152. New York \& Oxford: Oxford University Press, 1990.

UCHIYAMA Katsuo \& TAJIRI Tetsuya. ñKokusaku Imin no Jidaiò. In: Burajiru Imin Hatij 1 Nen Shi, pp. 85-139. São Paulo: Nihon Imin Hatijî Nen Shi Hensan Iinkai (org.), 1991.

UEHARA TetsusaburǾ Hakukoku no Imin Seigen Mondai. In: Hokkaido Teikoku Daigaku HǾkeikai Ronsǿ n. 3, pp. 1-21, 1934. Disponível em

<https://eprints.lib.hokudai.ac.jp/dspace/bitstream/2115/10615/1/3_p1-21.pdf> Acesso em: 22 de abril de 2019.

NAMURA YÎ ko \& DO NASCIMENTO, Anthony. ñ1933-1934 nen no burajiru shin kenpǾseitei gikai ni okeru hainichi undǾto nihon no gaimu tǿxyoku no taiø். In: RikkyǾDaigaku Raten Amerika KenkyI ShohǾ pp. 1-18, vol. 45, 2016. Disponível em

$<$ https://rikkyo.repo.nii.ac.jp/?action=pages_view_main\&active_action

=repository_view_main_item_detail\&item_id=15082\&item_no=1\&page_id=13\&block_id=49> Acesso em: 1 de maio de 2019.

\section{Documentos oficiais, jornais e revistas}

ANNAES DA ASSEMBLÉA NACIONAL CONSTITUINTE. Volume IV [1934]. Rio de Janeiro: Imprensa Nacional, 1935, pp. 211-216. Disponível em <http://bd.camara.gov.br/bd/handle/bdcamara /8227> Acesso em: 4 de junho de 2019.

A NOITE (RJ). Disponível em <http://memoria.bn.br/DocReader/DocReader.aspx?bib=348970_02\&PagFis= 2887> Acesso em: 22 de maio de 2019.

BURAJIRU JIHǽ(伯剌西爾時報). Disponível em <http://rakusai.nichibun.ac.jp/hoji/ichiran.php?title= Brasil> Acesso em: 27 de março de 2019.

CONSTITUIÇÃO DE 1934 NA CÂMARA DOS DEPUTADOS. Disponível em <https://www2.camara.leg.br /legin/fed/consti/1930-1939/constituicao-1934-16-julho-1934-365196publicacaooriginal-1-1.html> Acesso em: 6 de junho de 2019.

GAIMU SHá[Ministério das Relações Exteriores do Japão] (org.) Nihon GaikǾBunsho Shǿva ki II Dai 2 bu, Dai 2 kan. Nihon Kokusai RengǾKyǾxai, 1933, pp. 947-961. pp. 873-925. Nihon GaikǾBunsho ShǾva ki II Dai 2 bu, Dai 3 kan. Nihon Kokusai RengǾKyǾxai, 1934,

NIPPON SHIMBUN (日本新聞). Disponível em <http://rakusai.nichibun.ac.jp/hoji/ichiran.php?title=Nippon Shimbun> Acesso em: 1 de maio de 2019.

OSAKA MAINICHI SHIMBUN (大阪毎日新聞) de Shinbun Kiji Bunko (News Paper Clippings Collection), Kobe University Library Digital Archive, RIEB (Research Institute for Economics and Business Administration, Kobe University). Disponível em <http://www.lib.kobe-u.ac.jp/sinbun/eindex.html> Acesso em: 13 de maio de 2019.

REVISTA DO BRASIL, n. 62, fev/1921. Disponível em <https://bibdig.biblioteca.unesp.br/handle /10/26287> Acesso em: 6 de junho de 2019.

TOKYO NICHI NICHI SHIMBUN (東京日日新聞) de Shinbun Kiji Bunko (News Paper Clippings Collection), Kobe University Library Digital Archive, RIEB (Research Institute for Economics and Business Administration, Kobe University). Disponível em <http://www.lib.kobe-u.ac.jp/sinbun/eindex.html> Acesso em: 13 de maio de 2019.

\section{Fististorínias}

